\title{
Correction to: Magnetic Characterization of Ferromagnetic Shape Memory Components Under Defined Mechanical Loading
}

\author{
Fabian Ehle $^{1}$ (D) Peter Neumeister $^{1}$ (D) Eric Haufe $^{1} \cdot$ Holger Neubert $^{1}$ (D)
}

Published online: 2 March 2020

(C) ASM International 2020

\section{Correction to: Shap. Mem. Superelasticity} https://doi.org/10.1007/s40830-020-00266-2

The original article contains an error in Eqs. (2) and (11).

Equation (2) in should have been written as follows:

$$
\frac{\Delta H}{H} \approx \frac{2 d_{\mathrm{res}}}{d} \cdot \mu_{\mathrm{r}}=\frac{d_{\mathrm{gap}}-d}{d} \cdot \mu_{\mathrm{r}} \text {. }
$$

Equation (11) in should have been written as follows:

$$
\Phi=\tilde{B} A_{\Phi}(u)=\tilde{B} \cdot l_{0}\left(1+\frac{u}{l_{0}}\right) \cdot w
$$

Publisher's Note Springer Nature remains neutral with regard to jurisdictional claims in published maps and institutional affiliations.

The original article can be found online at https:// doi.org/10.1007/s40830-020-00266-2.

\footnotetext{
Fabian Ehle

fabian.ehle@ikts.fraunhofer.de

1 Fraunhofer IKTS, Fraunhofer Institute for Ceramic Technologies and Systems, Dresden, Germany
} 